\title{
Energy Efficiency in Rail Systems with Coasting Control Method Using GA and ABC Optimizations
}

\author{
Yağmur ARIKAN*, Tolga ŞEN, Ertuğrul ÇAM
}

\begin{abstract}
Today, reducing the energy consumption of rail systems is one of the issues that attract researchers' attention. There are many methods to reduce energy consumption and coasting control method has been used in this study. The driving modelling of the vehicle has been carried out by considering all parameters. A new objective function has been determined and for optimization, genetic algorithm (GA) and artificial bee colony (ABC) algorithm have been preferred. The study has been tested with the data of Ankaray metro line. When the proposed optimized driving has been compared with practical driving of the vehicle, the energy savings rate is $13.79 \%$ in $\mathrm{GA}$ and $13.45 \%$ in $\mathrm{ABC}$ for a driving. Despite these significant savings ratios, the increase in travel time has been calculated at $1.7 \%$ in $\mathrm{GA}$ and $1.55 \%$ in $\mathrm{ABC}$. When the obtained savings rates are considered annually, this study may greatly contribute to sustainable life.
\end{abstract}

Keywords: artificial bee colony algorithm; coasting control; dynamic model; energy consumption; genetic algorithm; rail systems

\section{INTRODUCTION}

Today, demand in energy consumption has been increasing due to population growth, economic and social developments. This leads to the rapid depletion of limited fossil fuels, the inefficient use of natural resources, the reduction of biodiversity and global warming. As everybody knows, these resources are finite; their sustainability is not possible in the future [1]. So, particularly after the oil crisis (1973) and Kyoto Protocol (1977), many countries-communities have taken various initiatives regarding the efficient use of energy for a sustainable life and a clean environment [2]. Organisation for Economic Co-operation and Development (OECD) of countries has taken important steps towards energy efficiency in energy policies [3] and the International Energy Agency has identified several scenarios to increase energy efficiency and reduce carbon dioxide emission by 2050 [4]. Also, European countries have aimed to reduce their energy consumption by $20 \%$ and increase their energy generation from renewable energy sources by $20 \%$ [5].

The transportation sector has a large share in the global world energy consumption. The transport sector in Turkey, which is among developing countries and has a population of more than 80 million, constitutes about $20-25 \%$ of total energy consumption. It is anticipated that this value will increase over time, according to the studies [6]. Moreover, this sector, which is responsible for $24 \%$ of $\mathrm{CO}_{2}$ emission in 2017, is considered as one of the most important causes of environmental pollution [7]. Therefore, efficiency principles in transportation systems provide advantages both in terms of proper use of resources and a clean liveable environment. Additionally, it is also important for budget investments, as energy resources are imported in many countries.

When we look at the energy policies in transportation in general, we see that urban transportation is recommended, efficiency standards in vehicles are improved, and the use of environment-friendly fuel and low-emission vehicles are encouraged. Urban rail systems are considered as a good solution to such problems due to their convenience, high capacity, safety, and reliability [8]. Moreover, these systems carry more passengers with less energy in less time than other transportation vehicles. However, the energy consumption of these systems, particularly of the metro systems, is high in daily operation, and there is an urgent need to reduce energy consumption in rail systems since a large percentage of the world population uses these public transport systems [9]. Due to the high frequency-services in such systems, energy efficiency studies in these systems will also significantly reduce the operational cost of the systems and contribute to the reduction of carbon dioxide emissions.

Since rail systems consist of many subsystems, the studies in the literature for reducing energy consumption vary. They are generally classified into two sub-sections. These are designing rail systems and driving the rail system vehicle. When the studies about the designing rail systems have been examined, $\mathrm{Su}$ and others analysed how the infrastructure and vehicle features of metro systems affect operational train energy consumption [9]. Açıkbaş and Söylemez compared sizes of different power systems in terms of efficient rail system design and found that the 1500 Direct Voltage (VDC) system is more beneficial than the 750 VDC system in terms of energy loss [10]. Ordody observed the properties of the existing ventilation system in the Budapest subway and proposed a new economic primary ventilation system considering the technical requirements [|11]. Baerro et al. investigated the use of energy storage systems super capacitors in terms of energy savings and stated that these systems provide about 18 $25 \%$ efficiency [12]. Meinert investigated the effects of hybrid energy storage units, and these units provided that energy stored up to $2.5 \mathrm{~km}$ and saved up to $10.8 \%$ [13]. The most important feature of these studies is that they are generally recommended for the lines to be newly constructed, not for the existing lines. Apart from this, although the energy storage systems provide a reasonable energy savings rate, they also increase the cost. Therefore, it is recommended to perform the required feasibility analysis before use. In the studies about driving the rail system vehicle, there are different subtitles such as velocity optimization, coasting control, use of regenerative energy and timetable optimization. Various optimization methods and mathematical equations are used in these subjects. Milroy developed a controller to minimize energy 
consumption using Bellman's Principle of Optimality [14], Chang and Sim used the genetic algorithm (GA) optimization method in coasting control to reduce energy consumption [15]. Howlett used the Pontryagin principle and the Kuhn-Tucker equations with a generalized approach on a line [16]. Ko et al. used Bellman's Dynamic Programming to calculate the optimal operation of a rail vehicle to minimize energy consumption [17]. Mandic et al. presented a model of a $25 \mathrm{kV}$ traction system. They used sequential quadratic programming considering acceleration, cruise, and braking in driving regime [18]. Montrone et al. indicated the effect of the combinations of train driving regimes on energy consumption. They used a mixed-integer linear problem algorithm considering different time constraints to reduce energy consumption [19]. Liu et al. reduced energy consumption by $10.90 \%$ on a downhill line by using a numerical method [20]. Fernandez et al. determined that $98 \%$ of the regenerative energy can be reused for short interval services [21].

The first noticeable point in these studies is that the effect of some parameters is either neglected or fixed in the modelling of the train movement. The second point is that some studies were tested only on straight test lines. However, considering the rail system's complexity, density, and the number of services, more realistic modelling is required. Therefore, one of the aims of this study is to prepare a dynamic model for the driving of the rail system with all the parameters and operational conditions. In this model, energy consumption has been tried to be reduced with the coasting control technique, which is one of the energy driving techniques. The reason for choosing this technique is that it can be used in all lines and does not increase the cost.

Another point that draws attention in the studies is that the amount of energy consumption corresponding to different travel times was investigated. However, in general, travel time varies inversely with the amount of energy consumption; that is, as travel time increases, energy consumption decreases. For this reason, in this study, rather than this logic, the actual energy consumption and travel time in practical driving of the vehicle have been found, and the energy consumption value has been tried to be reduced based on the actual travel time with the proposed method. Accordingly, a new objective function has been created and two different heuristic algorithms have been used for optimization. The first is the GA, which is frequently encountered in the literature, and the second is $\mathrm{ABC}$, which is not used in coasting control.

This study intends to test the new objective function on a real line with multiple stations that have different features. For this reason, the real data of Ankaray metro station, which serves in Ankara and is used extensively, has been used. The results of the study have been found successful in terms of travel time and energy consumption.

\section{TRAIN MOVEMENT MODEL AND DRIVING REGIMES}

The movement of the rail vehicle from one station to another station is dependent on Newton's motion law and is given in Eq. (1) [22-23]:

$$
\begin{aligned}
& m_{\mathrm{e}} \cdot a=F(v)-R-B(v) \\
& a=\frac{\partial^{2} x}{\partial t^{2}}=\frac{\partial v}{\partial t}
\end{aligned}
$$

where $m_{\mathrm{e}}(\mathrm{kg})$ is the effective mass of the vehicle, $a$ $\left(\mathrm{m} / \mathrm{sec}^{2}\right)$ is the acceleration of the vehicle, $F(\mathrm{~N})$ is the traction force, $B(\mathrm{~N})$ is the braking force, $R(\mathrm{~N})$ is the vehicle resistance force, $v(\mathrm{~m} / \mathrm{s})$ is the velocity of the vehicle, $t(\mathrm{~s})$ is the travel time, $x(\mathrm{~m})$ is the distance between two stations. The effective mass of the vehicle can be calculated by using Eq. (2) [23]:

$m_{\mathrm{e}}=m \cdot\left(1+r_{\mathrm{f}}\right)$

where $m(\mathrm{~kg})$ is mass of the vehicle, $r_{\mathrm{f}}$ is a rotary allowance, and it is usually assumed to be less than 0.2 [23]. In Eq. (1), the traction $(F)$ and braking forces $(B)$ are dependent on the mechanical characteristics of the motor or the type of the rail vehicle, and these forces are important in achieving the desired velocity value of a vehicle and obtaining the required acceleration/deceleration. Resistors $(R)$ have a negative effect on the movement of the vehicle and can be calculated by using Eq. (3):

$$
R=r(v)+r_{\mathrm{g}}(x)+r_{\mathrm{c}}(x)
$$

where $r(v)$ is the rolling resistance and depends on the velocity of the rail vehicle. It can be calculated by using Eq. (4) [24]:

$r(v) \cong a_{\mathrm{rr}}+b \cdot v+c \cdot v^{2}$

where $a_{\mathrm{rr}}, b$, and $c$ correspond to mass, mechanical, and air resistance, respectively. The other resistance is gradient resistance, $r_{\mathrm{g}}$ varies to level changes in track and can be calculated by using Eq. (5) [25]:

$r_{\mathrm{g}}(x)=m \cdot g \cdot \sin (\phi)$

where $g$ is the gravitational constant and $\phi$ is the gradient. $r_{\mathrm{c}}(x)$ is the curve resistance and can be calculated by using Eq. (6) [26]:

$r_{\mathrm{c}}(x)=\frac{d}{p-e}$

where $p$ is the radius of the curve and $d$ and $e$ are considered as follows:

(i) $d=0.65 \mathrm{~m}$,

(ii) $e=55 \mathrm{~m}$ for $p$ greater than $350 \mathrm{~m}$,

(iii) $e=65 \mathrm{~m}$ for $p$ between 250 and $350 \mathrm{~m}$.

Based on these equations, the total energy consumption of the vehicle while driving can be found as Eq. (7) [27]:

$E=\frac{\int F \cdot v \cdot \mathrm{d} t}{\eta_{\mathrm{t}}}+A \cdot t+\eta_{\mathrm{b}} \int B \cdot v \cdot \mathrm{d} t$ 
where $\eta_{\mathrm{t}}$ is the efficiency during the traction, $\eta_{\mathrm{b}}$ is the efficiency during the braking, $\mathrm{A}$ is the power of auxiliary services [27]. The most important factor that determines the energy consumption while driving is the driving regime of the vehicle. The rail vehicle can follow four different driving regimes as it travels from one station to another. These are acceleration, cruise, coasting, and braking which are shown in Fig. 1.

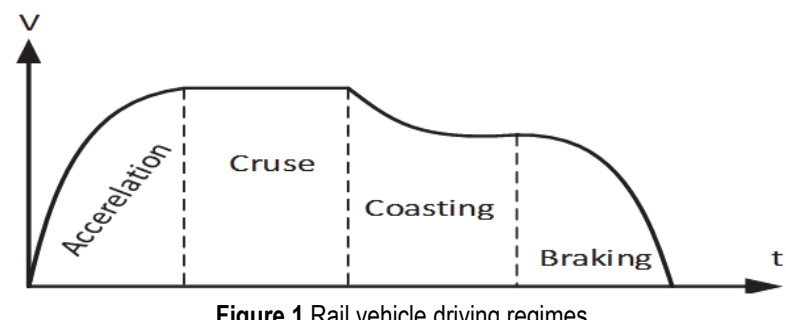

In the acceleration regime, the maximum power is given to the engine for the acceleration of the vehicle. The velocity of the rail vehicle is calculated by using Eq. (1). In the cruising regime, the velocity of the vehicle is constant. The applied traction force must be equal to the resistance force to keep the velocity at a constant value. In the coasting regime, which is important to reduce energy consumption, the vehicle does not consume energy, i.e., the engine is stopped [19]. In the braking regime, the braking force is applied either to decrease the vehicle of the vehicle or to ensure that the vehicle stops at the desired point [25]. It can be said that there are two different types of braking: mechanical and regenerative. In mechanical braking, the velocity of the vehicle is less than $6 \mathrm{~km} / \mathrm{h}$, and this braking does not contribute to energy saving. In regenerative braking, the velocity of the vehicle is greater than $7 \mathrm{~km} / \mathrm{h}$, and most of the energy consumed in this braking can be reused by various methods [28].

\section{ENERGY CONSUMPTION IN RAIL SYSTEMS}

Energy consumption in rail systems takes place in two different sections; traction and non-traction. While traction energy consumption means the energy used for rail vehicles, power system, transmission and auxiliary systems of the vehicles in service mode, non-traction energy means the energy used for stations, depots, airconditioned elevators, signalling, groundwater pumps, etc. [8], and this distribution is shown in Fig. 2.
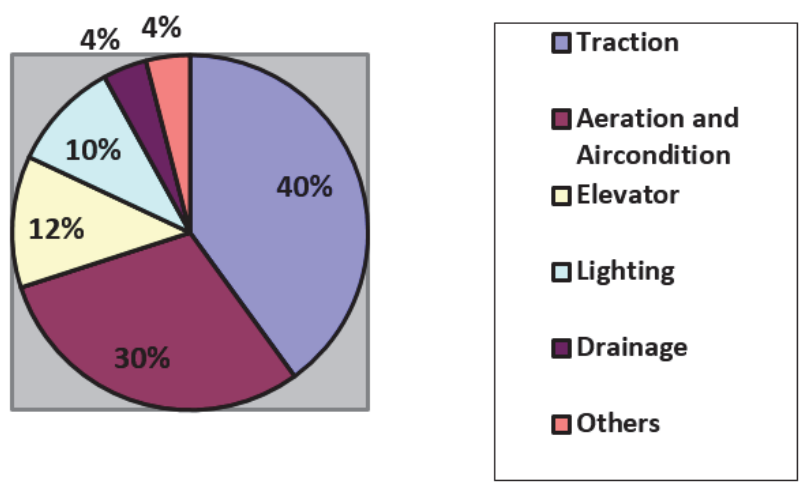

Figure 2 Energy consumption in rail systems
As can be seen in Fig. 2, traction energy consumption has the most important role in energy consumption of a rail system, and energy consumption in rail systems takes place in many areas. Therefore, energy efficiency studies also vary, and they are listed in Tab. 1, generally. While nontraction methods are generally related to the improvement of various comfort functions, others generally include methods for the use of regenerative energy, energyefficient driving methods, and energy-efficient rail system design methods [8].

Table 1 Energy saving methods in rail systems

\begin{tabular}{|l|l|}
\hline \multicolumn{1}{|c|}{ Non-traction methods } & \multicolumn{1}{c|}{ Traction methods } \\
\hline Temperature control & $\begin{array}{l}\text { Regenerative braking; energy } \\
\text { recovery/timetable optimization/ } \\
\text { energy storage devices }\end{array}$ \\
\hline $\begin{array}{l}\text { Demand control/ventilation/ } \\
\text { heating/lighting }\end{array}$ & $\begin{array}{l}\text { Energy-efficient driving. } \\
\text { Eco-driving/coasting control }\end{array}$ \\
\hline $\begin{array}{l}\text { Optimal regulation waste heat } \\
\text { recovery/underground/subway } \\
\text { station/escalator }\end{array}$ & $\begin{array}{l}\text { Energy-efficient traction system; } \\
\text { reduction power supply, line, } \\
\text { electrical loss } \\
\text { Vehicle mass reduction-lightweight } \\
\text { material }\end{array}$ \\
\hline
\end{tabular}

In this study, energy driving techniques have been used to reduce the energy consumption of the rail system, and coasting control has been preferred for this purpose. The reason for using this method is that it is easy, can be used in any line, and does not increase the cost.

\section{MODELLING AND ANALYSIS \\ 4.1 Driving Modelling}

It is necessary to dynamically model the rail system driving, whichever method is used to reduce the energy consumption of the rail system vehicle. Rail system vehicle driving takes place continuously, and many factors such as vehicle-related effects, track-related factors, operational restrictions affect this driving momentarily, i.e., these parameters constantly change. In the study, dynamic driving modelling has been carried out by using Matlab software, and continuous-time equations for modelling have been converted to discrete-time by using Eq. (8) RO Eq. (14) [27, 28]:

$\left[\frac{\dot{x}_{j}}{\dot{v}_{j}}\right]=\left[\frac{v_{j}}{\frac{1}{m_{\mathrm{e}}}\left(F_{j}(v)-R-B_{j}(v)\right)}\right]$

$t_{\text {step }}=\frac{t}{N} ; j=0,1,2, \ldots, N$

$v_{j+1}=v_{j}+\left(a_{j} \cdot t_{\text {step }}\right)$

$x_{j+1}=x_{j}+\left(\frac{v_{j}+v_{j+1}}{2}\right) \cdot t_{s t e p}$

$E_{j+1}=E_{j}+\left(\left(F_{j+1} \cdot v_{j+1}\right) \cdot t_{\text {step }}\right)$ 
$E r_{j+1}=E_{r e j}+\left(\left(B_{j+1} \cdot v_{j+1}\right) \cdot t_{\text {step }}\right) \Leftrightarrow \ldots$

$v_{j+1} \geq 1.94 \mathrm{~m} / \mathrm{sec}$

$x_{s d}=\frac{v_{f}^{2}}{2 \cdot a_{f}}$ where $x_{j}, v_{j}, E_{j}$ express location, velocity, and energy consumption of the vehicle at step $\mathrm{j}$ respectively, and $t_{\text {step }}$ represents step size. $E_{r}$ is the regenerative energy amount of the vehicle. $x_{s d}, v_{f}$, and $a_{f}$ correspond to the safe braking distance, current velocity of the vehicle, and braking acceleration of the vehicle, respectively. The flow chart of the prepared model is given in Fig. 3 .

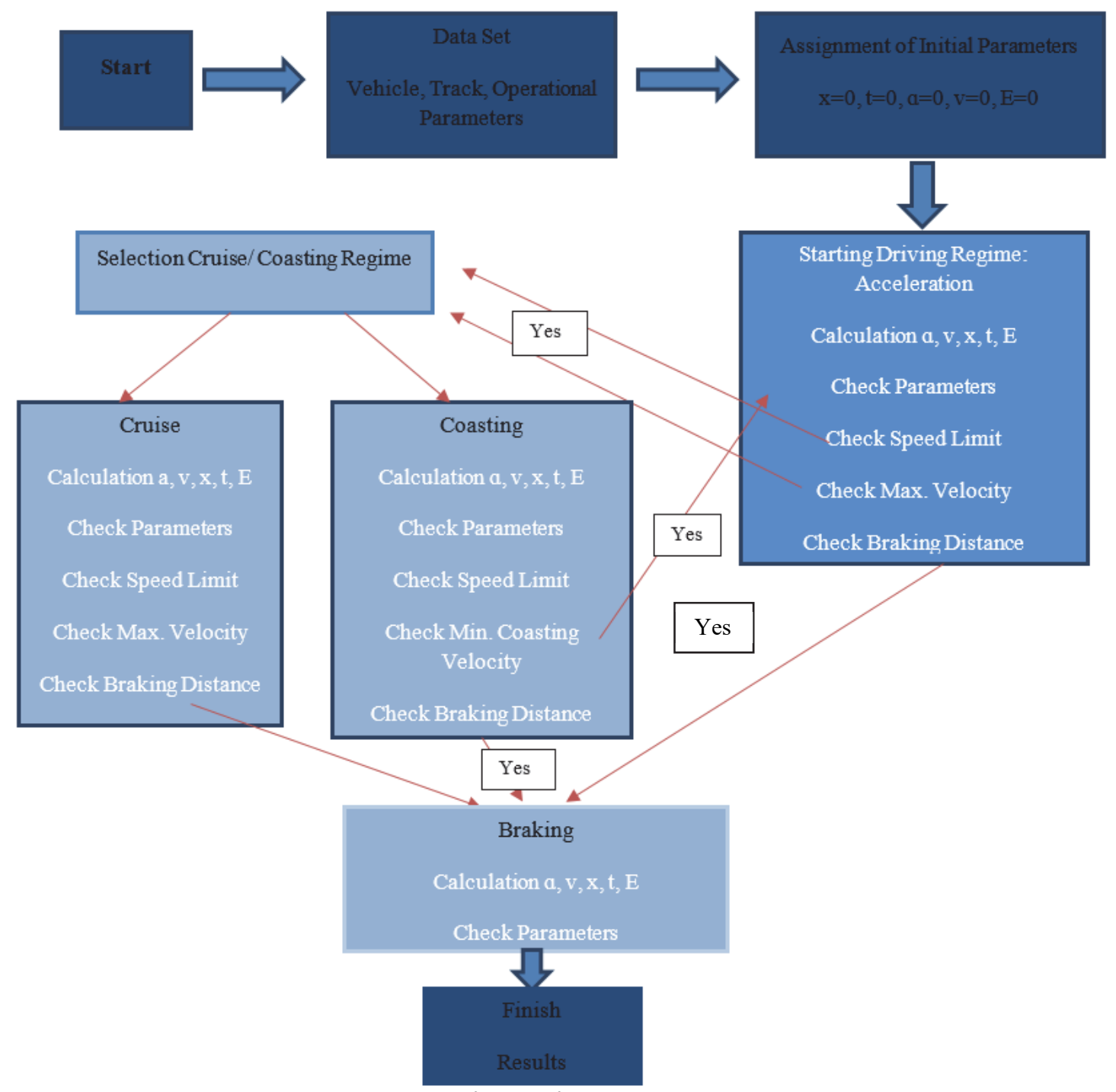

Figure 3 The flowchart of driving modelling

\subsection{The Optimization of Energy Consumption}

In the study, the coasting control method has been preferred to reduce energy consumption. Contrary to many studies in the literature, instead of reducing energy consumption during different travel times or predetermined travel time, energy consumption has tried to be optimized based on actual travel time. Accordingly, a new objection function has been created, whose input parameters are the acceleration and braking force of the vehicle and output parameters are coasting start-finish locations, and the minimum coasting finish velocity value. When working with these values, a penalty factor has been assigned based on delays in the actual travel time. This penalty factor has been determined as 1.01 for delays up to $2.5 \%$ and as 1.05 for delays greater than $2.5 \%$. The objective function and related equations are as Eq. (15) to Eq. (20):

$$
\begin{aligned}
& F_{\min } \leq F \leq F_{\max } \\
& B_{\min } \leq B \leq B_{\max } \\
& t=0 ; x(0)=0 ; v(0)=0 ; \\
& x(N)=x ; v(N)=0 \\
& f\left(\begin{array}{c}
F_{\mathrm{act}}^{N}, B_{\mathrm{act}} \\
j=0
\end{array}\right) \rightarrow t_{\mathrm{act}}, E_{\mathrm{act}} \\
& f(F, B) \rightarrow t, E
\end{aligned}
$$




$$
\begin{aligned}
& t \leq t_{\mathrm{act}} \cdot 1.025 \rightarrow p f=1.01 \\
& t \succ t_{\mathrm{act}} \cdot 1.025 \rightarrow p f=1.05 \\
& \text { objfunc. }=\min \left[\left(\sum E\right) \cdot p f\right] \rightarrow \ldots \\
& \rightarrow x_{c s}, x_{c f}, v_{c f} \rightarrow E_{o p}, t_{o p}
\end{aligned}
$$

where $F_{\text {act }}, B_{\text {act }}, t_{\text {act }}, E_{\text {act }}$ are the actual traction force, braking force, travel time, and energy consumption values at actual driving, respectively. $p f$ is the penalty factor, objfunc. is the proposed objective function. $x_{\mathrm{cs}}, x_{\mathrm{cf}}, v_{\mathrm{cf}}$ is the coasting start and finishing location value and minimum coasting velocity value. $E_{\mathrm{op}}$ and $t_{\mathrm{op}}$ is the optimal energy consumption and optimal travel time value.

Two heuristic algorithms have been used in optimization prosses. These are GA, which is frequently used in the literature, and $\mathrm{ABC}$, which is not used for coasting control in the literature. The flow diagram of the optimization process in the study is shown in Fig. 4.

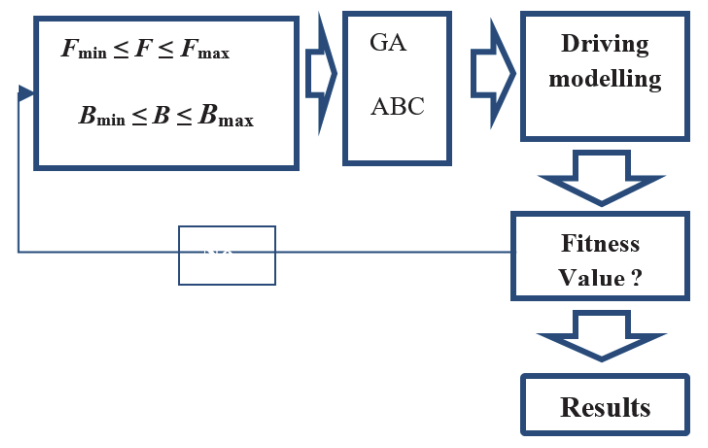

Figure 4 The flowchart of the optimization process

\subsubsection{Genetic Algorithm (GA)}

It is one of the artificial intelligence methods inspired by Darwin's natural selection-evolution principle, and it was suggested by John Holland in 1970 [29]. The biological information that must be known in this algorithm is the terms gene, chromosome, and population. A gene is the smallest significant unit, multiple genes make up the chromosomes, and the population is a community of chromosomes. Each chromosome is randomly selected and has a fitness value for the solution of a problem. After calculating the fitness value of all chromosomes in the population, some of them are selected using various methods such as roulette, steady-state, and tournament to produce the next generation. The crossover operator is used to create new chromosomes with better qualifications than the previous generation to investigate the potential of the present gene pool. If the population does not contain all the required information, the desired chromosomes are formed with the help of a mutation operator. Generally, the steps of the genetic algorithm can be listed as follows [29]:

Step 1. Initialization/Random generating initial population. Step 2. Calculating the fitness value of each chromosome. Step 3. Selecting individuals with high fitness value for new generating.

Step 4. Applying crossover and mutation.

Step 5. If the stopping criteria have not met, return to Step 2 [29].

\subsubsection{Artificial Bee Colony Algorithm}

This algorithm was prepared by Dervis Karaboga, considering the intelligent behaviour of bees and their search for food. The bees are divided into three groups according to their duties; employed bees, onlookers, and scout [30]. In this optimization algorithm, some of the assumptions are as follows:

The number of employed bees must be equal to total food sources and the number of onlooker bees. When the amount of nectar is finished, the employed bee becomes a scout bee. Generally, the steps of the artificial bee colony algorithm can be listed as follows [30]:

Step 1: Initialization/Creating initial food sources.

Step 2: Repeat.

Step 3: Calculation of food source's nectar amount with employed bees.

Step 4: Calculation of food source's probability value and an onlooker bee selects a food source using Eq. (21):

$$
p_{i}=\frac{f i t_{i}}{\sum_{n=1}^{S N} f i t_{n}}
$$

where $p_{i}$ is the probability value of food source, $f i t_{i}$ is the fitness value of the solute at the position $\mathrm{i}$ and $S N$ is the number of food sources.

Step 5: Produce the new food position using Eq. (22):

$$
y_{i j}=z_{i j}+\phi_{i j} \cdot\left(z_{i j}+z_{k j}\right) k \in 0,1 \ldots S N, j \in 0,1 \ldots D
$$

where $D$ is the number of parameters, $\phi_{i j}$ is a random number between $(-1,1), z_{i j}$ is a visual comparison of two food positions by a bee.

Step 6: Selection of food source region according to the results of probability values.

Step 7: Qualification of the criteria: production of scout bee and replacing a food source with another food source using Eq. (23):

$z_{i}^{j}=z_{\min }^{j}+\operatorname{rand}(0,1) \cdot\left(z_{\max }^{j}-z_{\min }^{j}\right)$

where $i=1,2, \ldots, S N ; j=1,2, \ldots, D$, and $z_{\min }$ and $\mathrm{z}_{\max }$ are the lower and upper limits of the parameter at step $j$.

Step 8: Memorize the best solution.

Step 9: Return to step 2 until stop criterion.

\section{CASE STUDY \\ 5.1 Description of the Line}

The effectiveness of the algorithms and the proposed method developed in the Matlab software have been tried to be evaluated on a real metro line with multi stationsdifferent features after the investigated on the test lines. For this purpose, the practical data of Ankara, Ankaray Metro Line have been used in the study. The metro line consists of eleven stations, the total line length is $8.527 \mathrm{~km}$, and the number of daily services is approximately 175 . The names of the stations are listed in alphabetical order, and the lengths between stations are given in Tab. 2 . 
Table 2 The length between stations

\begin{tabular}{|c|c|}
\hline Name of Station & Length $/ \mathrm{m}$ \\
\hline A-B (Aşti-Emek) & 608 \\
\hline B-C (Emek-Bahçelievler) & 869 \\
\hline C-D (Bahçelievler-Beşevler) & 798 \\
\hline D-E (Beşevler-Anadolu) & 804 \\
\hline E-F (Anadolu-Maltepe) & 531 \\
\hline F-G (Maltepe-Demirtepe) & 946 \\
\hline G-H (Demirtepe-KızılayMilliIrade) & 715 \\
\hline H-I (KızılayMilliIrade-Kolej) & 977 \\
\hline I-J (Kolej-Kurtuluş) & 551 \\
\hline $\mathrm{J}$-K(Kurtuluş-Dikimevi) & 950 \\
\hline
\end{tabular}

The speed limits have been taken as $18 \mathrm{~m} / \mathrm{sec}$ and 15 $\mathrm{m} / \mathrm{sec}$ between 350 and 500 meters of G-H, 450-600 meters of $\mathrm{J}-\mathrm{K}$ respectively due to curves. The slope of the route has $0.15 \%$ and $0.22 \%$. The data of the vehicle used in the line are listed in Tab. 3.

Table 3 The vehicle characteristics

\begin{tabular}{|l|c|}
\hline \multicolumn{1}{|c|}{ Characteristics } & Value \\
\hline Vehicle mass & $40.500,0 \mathrm{~kg}$ \\
\hline Maximum speed & $22.22 \mathrm{~m} / \mathrm{s}$ \\
\hline Maximum acceleration & $1.10 \mathrm{~m} / \mathrm{s}^{2}$ \\
\hline Maximum braking & $1.35 \mathrm{~m} / \mathrm{s}^{2}$ \\
\hline The rated voltage & $750 \mathrm{VDC}$ \\
\hline
\end{tabular}

\subsection{The Actual Driving}

Before trying the recommended method, the actual driving model of the vehicle in the line has been modelled. This driving is also called time-focused driving. In this driving, if there is no restriction on line, the vehicle accelerates up to the maximum velocity value according to the characteristics of the vehicle, then it goes at a constant velocity up to the braking distance, and when the braking distance comes, it switches to braking. The velocity-time, location-time, and energy-time graphs of actual driving modelling for two sample different lines that have different features such as speed limit, length are shown in Fig. 5 and Fig. 6, respectively. The velocity-time graph is shown twice to better observe the location and energy consumption values of the vehicle according to the velocity values.

Table 4 The results of actual driving

\begin{tabular}{|c|c|c|c|}
\hline Station & $\begin{array}{c}\text { Travel time / } \\
\text { sec }\end{array}$ & $\begin{array}{c}\text { Energy Consumption } \\
/ \mathrm{kJ}\end{array}$ & $\begin{array}{c}\text { Regenerative } \\
\text { Energy / kJ }\end{array}$ \\
\hline A-B & 46.65 & 13143.1842 & 6.9029 \\
\hline B-C & 58.58 & 15100.2699 & 6.9029 \\
\hline C-D & 55.6 & 14567.2764 & 6.9029 \\
\hline D-E & 55.38 & 14613.9133 & 6.9029 \\
\hline E-F & 43.27 & 12565.2194 & 6.9029 \\
\hline F-G & 61.94 & 15678.2348 & 6.9029 \\
\hline G-H & 53.92 & 13483.2069 & 7.479 \\
\hline H-I & 63.2 & 15911.4194 & 6.9029 \\
\hline I-J & 44.2 & 12715.1238 & 6.9029 \\
\hline J-K & 68.15 & 18581.7943 & 10.174 \\
\hline
\end{tabular}

As a result of modelling for all stations, the actual travel time, energy consumption, and the amount of regenerative energy have been calculated. These values are listed in Tab. 4.

As can be seen from Tab. 4, the total travel time of the vehicle from the starting station (A) to the ending station $(\mathrm{K})$ is 550.89 seconds. The total energy consumption for this driving is approximately 146.4 MJ. Additionally, the amount of released energy during the braking of the vehicle and burned in the braking resistors has been calculated.
These values have been found close to each other in most stations. The reasons for this can be listed as follows: There is no restriction on the lines, most of the line is in the tunnel during braking and the forces acting on the vehicle are approximately the same. It is noteworthy that this value is approximately $40 \%$ of the total energy consumption.
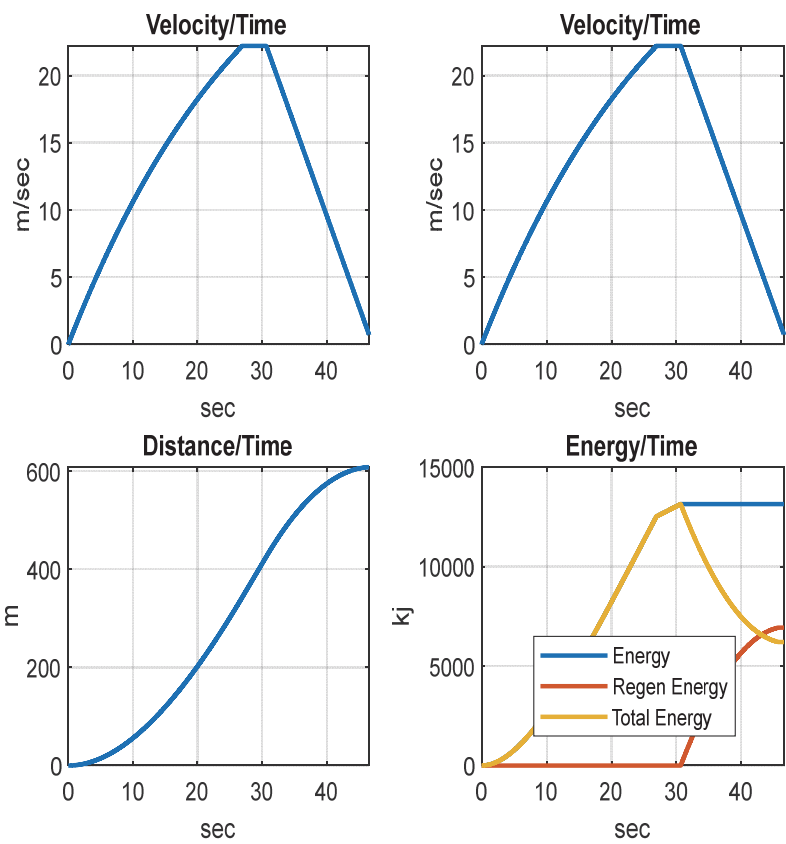

Figure 5 The velocity/time, the location/time, and the energy/time graphs between A-B station
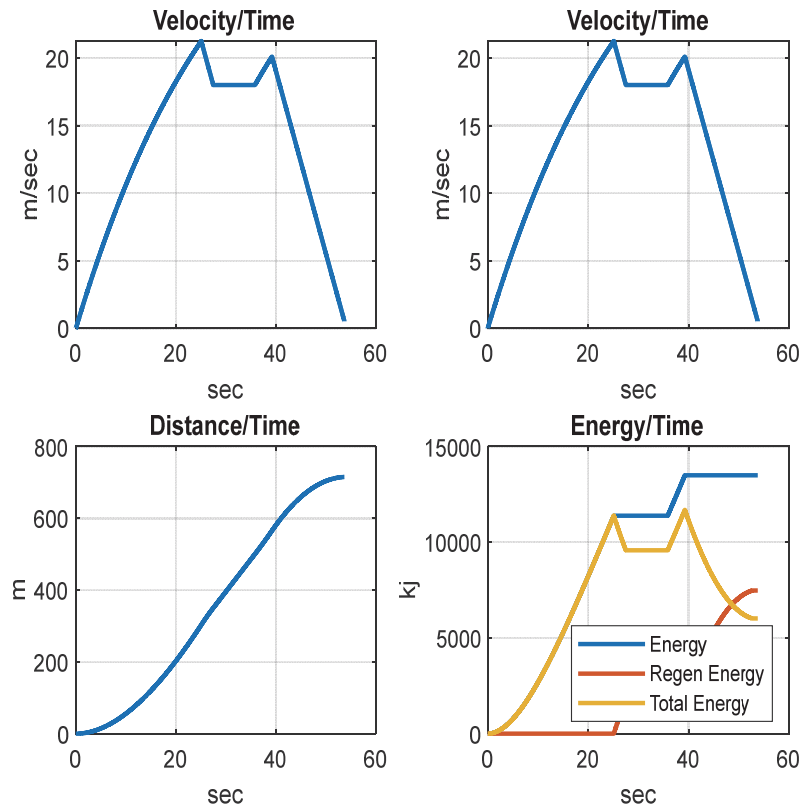

Figure 6 The velocity/time, the location/time, and the energy/time graphs between G-H station

\subsection{The Recommended Driving for Energy Optimization}

The energy-saving driving techniques have been investigated, and the Coasting Control method, one of these techniques, has been preferred to reduce energy consumption. For this purpose, unlike the literature, while optimizing energy consumption, instead of examining the effect of different travel times, it has been aimed to reduce energy consumption based on the actual travel time. In this 
way, it has been ensured that the increase in travel time, which is the most undesirable thing for passengers, is minimal.

For this driving, both the Eq. (15) to Eq. (20) and the driving model prepared in Matlab have been used together. Two different heuristic algorithms, GA and $\mathrm{ABC}$, have been preferred for optimization. GA has been preferred because it gives good results in these issues in the literature, while $\mathrm{ABC}$ has been preferred because it is not used in the literature in coasting control and gives good results in other optimization problems.

The parameters used in GA and $\mathrm{ABC}$ have been selected after a few attempts. In these trials, convergence to the most appropriate fitness value and computation time of the algorithm have been examined. The final values of these parameters are given in Tab. 5 .

Table 5 The parameters of $G A$ and $A B C$ optimization

\begin{tabular}{|l|l|l|}
\hline \multirow{4}{*}{ GA } & Population size & 200 \\
\cline { 2 - 3 } & Selection function & Stochastic uniform \\
\cline { 2 - 3 } & Crossover function & Single point \\
\cline { 2 - 3 } & Mutation rate & 0.01 \\
\cline { 2 - 3 } & Crossover fraction & 0.8 \\
\hline \multirow{2}{*}{ ABC } & The number of colony size & 20 \\
\cline { 2 - 3 } & The number of cycles & 1000 \\
\hline
\end{tabular}

Table 6 The coasting start and finish location value and coasting finishing velocity value with $G A$ and $A B C$

\begin{tabular}{|c|c|c|c|c|c|c|}
\hline \multirow{2}{*}{ Station } & \multicolumn{3}{|c|}{$\mathrm{GA}$} & \multicolumn{3}{c|}{$\mathrm{ABC}$} \\
\cline { 2 - 7 } & $x_{c s} / \mathrm{m}$ & $x_{c f} / \mathrm{m}$ & $v_{c f} / \mathrm{m} / \mathrm{s}$ & $x_{c s} / \mathrm{m}$ & $x_{c f} / \mathrm{m}$ & $v_{c f} / \mathrm{m} / \mathrm{s}$ \\
\hline A-B & 341.4 & 440.2 & 21.27 & 347.5 & 438.7 & 21.39 \\
\hline B-C & 342.8 & 741.6 & 18.51 & 343.4 & 741.0 & 18.56 \\
\hline C-D & 343.5 & 658.7 & 19.4 & 343.7 & 658.7 & 19.4 \\
\hline D-E & 343.3 & 665.5 & 19.33 & 347.7 & 665.9 & 19.32 \\
\hline E-F & 341.5 & 349.1 & 22.15 & 340.8 & 348.8 & 22.16 \\
\hline F-G & 344.6 & 829.9 & 17.5 & 340.5 & 825.0 & 17.9 \\
\hline G-H & - & - & - & - & - & - \\
\hline H-I & 348.2 & 865.0 & 17.32 & 343.3 & 866.5 & 17.27 \\
\hline I-J & 341.5 & 372.4 & 21.95 & 343.5 & 373.5 & 21.9 \\
\hline J-K & 340.5 & 352.7 & 22.1 & 342.2 & 355.4 & 21.92 \\
\hline
\end{tabular}

By using these values, travel times, and energy consumption values in the proposed driving have been calculated, and they are listed in Tab. 7.

Table 7 The travel time and energy consumption values with $G A$ and $A B C$

\begin{tabular}{|c|c|c|c|c|}
\hline \multirow{2}{*}{ Station } & \multicolumn{2}{|c|}{ GA } & \multicolumn{2}{c|}{ ABC } \\
\cline { 2 - 5 } & $\begin{array}{c}\text { Travel } \\
\text { Time }\end{array}$ & $\begin{array}{c}\text { Energy } \\
\text { Consumption }\end{array}$ & $\begin{array}{c}\text { Travel } \\
\text { Time }\end{array}$ & $\begin{array}{c}\text { Energy } \\
\text { Consumption }\end{array}$ \\
\hline A-B & 46.93 & 12518.066 & 46.78 & 12566.3685 \\
\hline B-C & 59.94 & 12519.7313 & 59.88 & 12524.7273 \\
\hline C-D & 56.33 & 12526.3926 & 56.33 & 12526.3926 \\
\hline D-E & 56.59 & 12524.7273 & 56.32 & 12566.3685 \\
\hline E-F & 43.27 & 12530.5381 & 43.2 & 12549.2448 \\
\hline F-G & 64.22 & 12533.0593 & 63.97 & 12895.4041 \\
\hline G-H & - & - & - & - \\
\hline H-I & 65.72 & 12561.3645 & 65.93 & 12521.3966 \\
\hline I-J & 44.29 & 12524.3051 & 44.03 & 12526.3926 \\
\hline J-K & 69.05 & 12518.066 & 69.11 & 12517.463 \\
\hline
\end{tabular}

With the help of two algorithms, using the different acceleration and braking forces to minimize energy consumption, the vehicle's coasting start and finishing location points and the minimum velocity value to stop the driving with the coasting regime have been found for all stations. Tab. 6 shows coasting starting location $\left(x_{c s}\right)$, coasting finish location $\left(x_{c f}\right)$, and coasting finish speed $\left(v_{c f}\right)$ values for each station found by GA and ABC. This method could not be used because the speed limit between the G-H stations is between the distances between which the coasting regime will be applied. However, even if it is not included in the study, a different driving technique can be tried by driving at a slightly lower speed than the maximum speed limit between those stations. The actual values between these stations have been taken as a basis in comparisons for all stations.

\subsection{The Comparison of Driving Modes}

Finally, various comparisons have been made. The results of the algorithms have been compared with each other and compared with the actual driving results. The comparison of velocity/time and energy/time graphs for an example station is shown in Fig. 7a and Fig. 7b, respectively.

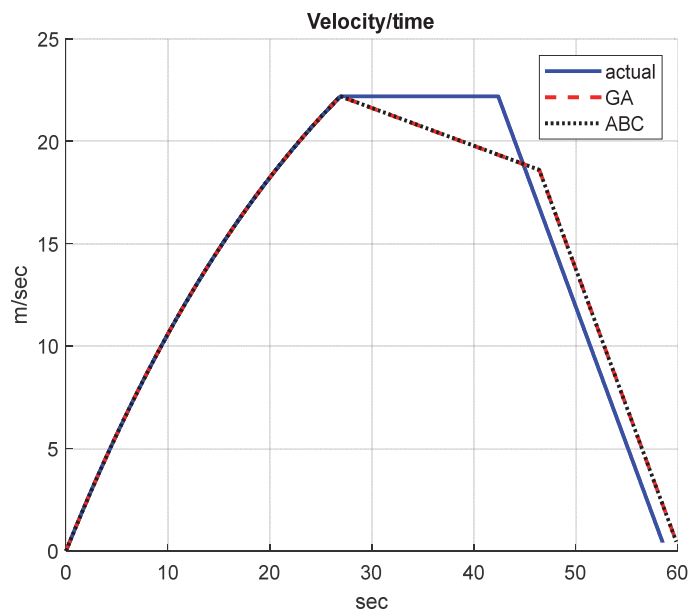

(a)

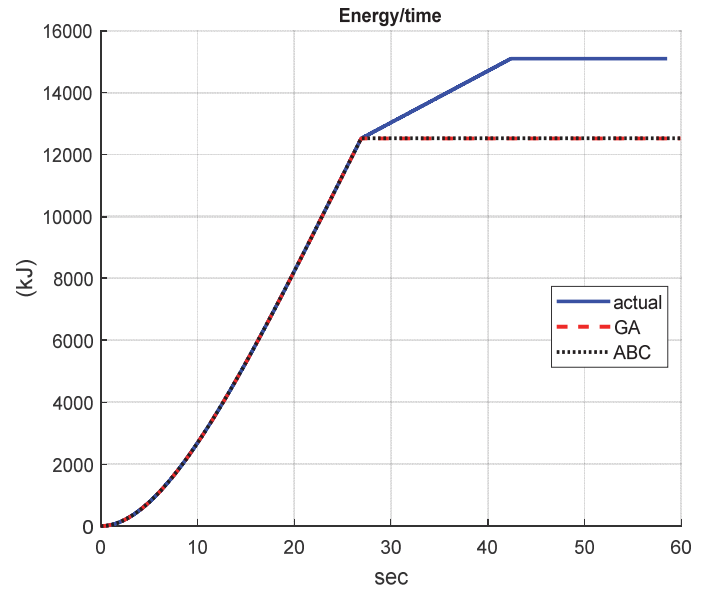

(b)

Figure 7 (a) The comparison of velocity/time graphs between B-C station, (b) The comparison of energy/time graphs between $B-C$ station

The comparative travel time and energy consumption values for all stations are given in Tab. 8 .

Table 8 The comparison of results

\begin{tabular}{|l|c|c|}
\hline & Travel time / s & Energy Consumption / MJ \\
\hline Actual Driving & 550.89 & 146.4 \\
\hline GA-Proposed Method & 560.26 & 126.2 \\
\hline ABC-Proposed Method & 559.47 & 126.7 \\
\hline
\end{tabular}

As seen, this method is not used between a station $(\mathrm{G}-$ $\mathrm{H})$. However, it is observed that $13.79 \%$ of energy savings in GA and $13.45 \%$ in $\mathrm{ABC}$. On the other hand, since the 
proposed method is based on the actual travel time, the increase in the total travel time has been found to be between $1.7 \%$ and $1.55 \%$, which can be easily compensated by the waiting times at the stations. Considering that these earnings have been obtained for a single driving, this earning rate will have a great impact on the economy and emission, considering daily, monthly, and annual trips. When the performance of the algorithms has been evaluated among themselves, although both give very close results, it seems that GA gives better results in terms of both travel time and energy consumption. Also, the shorter computation time of the genetic algorithm is another positive side.

\section{CONCLUSIONS}

In this study, it is aimed to reduce the energy consumption of the rail systems, which are frequently preferred and used extensively in transport, without exceeding the actual travel time. Dynamic modelling of the driving has been carried out by considering all the parameters affecting the driving of the vehicle. To reduce energy consumption, coasting control, which is one of the efficient driving techniques, has been preferred, and a new purpose function has been created. According to this function, GA and $\mathrm{ABC}$ optimization methods have been preferred to determine the driving dynamics of the vehicle. After the test studies, the study has been tried on the real metro line with multiple stations with different features. The results of the study have been found successful since it provides a significant energy savings rate. The other benefit is that increase in travel time is minimum, and the passengers are not adversely affected.

\section{Acknowledgements}

This work is supported by Kırıkkale University Scientific Research and Projects Coordination Office with grant number 2018/016.

\section{REFERENCES}

[1] Meadows, D., Randers, J., \& Meadows, D. (2012). Limits to Growth-The 30 Year Update, Earthscan. United States, Chelsea Green Publishing Company. https://doi.org/10.4324/9781849775861

[2] World Energy Council (2010). Energy Efficiency: A Recipe for Success.Retrieved fromhttps://www.worldenergy.org/ assets/downloads/PUB_Energy_Efficiency_A_Recipe_For_Success_2010_WEC.pdf.

[3] OECD. (1999). Energy: The Next Fifty Years. Retrieved fromhttps://www.oecd.org/futures/17738498.pdf.

[4] IEA. (2019). Energy Efficiency 2019. Retrieved from https://www.iea.org/reports/energy-efficiency-2019.

[5] European Commission (2014). Taking stock of the Europe 2020 strategy for smart, sustainable and inclusive growth. Proc. Annual Conference of Metallurgists, Brussels.

[6] Korkmaz, E. \& Akgüngör, A. (2019). Flower pollination algorithm approach for the transportation energy demand estimation in Turkey: model development and application. Energy Sources, Part B: Economics, Planning, and Policy, 13(11-12), 429-447. https://doi.org/10.1080/15567249.2019.1572835

[7] IEA. (2019). Transport. Retrieved from: https://www.iea.org/tcep/transport/.
[8] Gonzalez-Gil, A., Palacin, R., Batty, P., \& Powell, J. P. (2014). A systems approach to reduce urban rail energy consumption. Energy Conversion and Management, 80, 509524. https://doi.org/10.1016/j.enconman.2014.01.060

[9] Su, S., Tang, T., \& Wang, Y. (2016). Evaluation of strategies to reducing traction energy consumption of metro systems using an optimal train control simulation model. Energies, 9(2), 1-19. https://doi.org/10.3390/en9020105

[10] Açıkbaş, S. \& Söylemez, M. T. (2004). Energy loss comparison between 750 VDC and 1500 VDC power supply systems using rail power simulation. Computers in Railways IX, 74, 951-960.

[11] Ordody, P. (2000). Thermal comfort in the passenger areas of the Budapest metro. Periodica Polytechnica Mechanical Engineering, 44(2), 309-317.

[12] Barrero, R., Mierlo, J. V., \& Tackoen, X. (2008). Energy savings in public transport. IEEE Vehicular Technology Magazine, 3(3), 26-36.

https://doi.org/10.1109/MVT.2008.927485

[13] Meinert, M. (2009). New mobile energy storage system for rolling stock. 13th European Conference on Power Electronics and Applications, Spain.

[14] Milroy, I. P. (1980). Aspects of Automatic Train Control. $\mathrm{PhD}$ thesis of Loughborough University, UK.

[15] Chang, C. S. \& Sim, S. S. (1997). Optimizing train movements through coast control using genetic algorithms. IEEE Proceedings Electric Power Applications, 144(1), 6573. https://doi.org/10.1049/ip-epa:19970797

[16] Howlett, P. (2000). The optimal control of a train. Annals of Operations Research, 98, 65-87. https://doi.org/10.1023/A:1019235819716

[17] Ko, H., Koseki, T., \& Miyatake, M. (2004). Application of dynamic programming to optimization of running profile of a train. Computers in Railways IX, 74(10), 1-10.

[18] Mandic, M., Uglesic, I., \& Milardic, V. (2011). Method for optimization of energy consumption of electrical trains. International Review of Electrical Engineering, 6(1), 292299

[19] Montrone, T., Pellegrini, P., \& Nobili, P. (2017). Energy consumption minimization problem in a railway network. Transportation Research Procedia, 22, 85-94. https://doi.org/10.1016/j.trpro.2017.03.013

[20] Liu, W., Tang, T., Su, S., Yin, J., Cao, Y., \& Wang, C. (2019). Energy efficient train driving strategy with considering the steep downhill segment. Processes, 7(2), 117. https://doi.org/10.3390/pr7020077

[21] Fernandez, A., Fernandez, A., Cucala, A. P., \& Falvo, M. C. (2019). Energy efficiency and integration of urban electrical transport systems: EVs and metro-trains of two real European lines. Energies, 12(3), 1-20. https://doi.org/10.3390/en12030366

[22] Li, K. \& Gao, Z. (2007). An improved equation model for the train movement. Simulation Modelling Practice and Theory, 15(9), 1156-1162. https://doi.org/10.1016/j.simpat.2007.07.006

[23] Lu, S. (2011). Optimizing Power Management Strategies for Railway Traction Systems. PhD thesis of Birmingham University, UK.

[24] Davis, S. C. \& Diegel, S. W. (2009). Transportation Energy Data Book. $20^{\text {th }} \quad$ Ed., Washington DC. https://doi.org/10.2172/970887

[25] Keskin, K. \& Karamancioğlu, A. (2017). Energy efficient train operation using nature-inspired algorithms. Journal of Advanced Transportation, 5, 1-12. https://doi.org/10.1155/2017/6173795

[26] Lukaszewicz, P. (2001). Energy Consumption and Running Time for Trains, PhD thesis of KTH Railway Technology, Sweden.

[27] Brenna, M., Foiadelli, F., \& Longo, M. (2016). Application of genetic algorithms for driverless subway train energy 
optimization. International Journal of Vehicular Technology, 2, 1-14. https://doi.org/10.1155/2016/8073523

[28] Gkortzas, P. (2013). Study an Optimal Train Movement for Minimum Energy Consumption. MSc thesis of Malardalen University, Sweden.

[29] McCall, J. (2005). Genetic Algorithms for modelling and optimization. Journal of Computational and Applied Mathematics, 184(1), 205-222. https://doi.org/10.1016/j.cam.2004.07.034

[30] Karaboğa, D., Görkemli, B., Öztürk, C., \& Karaboğa, N. (2014). A comprehensive survey: artificial bee colony (ABC) algorithm and applications. Artificial Intelligence Review, 42(1), 21-57. https://doi.org/10.1007/s10462-012-9328-

\section{Contact information:}

Yağmur ARIKAN, PhD

(Corresponding author)

Department of Information Systems and Technology,

Sivas Cumhuriyet University

E-mail: yagmurarikan@gmail.com

Tolga SEN, PhD Student

Department of Electric and Electronic Engineering

Kirikkale University

E-mail: eem.tolga@gmail.com

\section{Ertugrul CAM, Professor}

Department of Electric and Electronic Engineering

Samsun University

E-mail: ertugrul_cam@yahoo.com 